\title{
Efficient halal bleeding, animal handling, and welfare: a holistic approach for meat quality
}

\begin{abstract}
Traditional halal slaughter and other forms of religious slaughter are still an issue of debate. Opposing arguments related to pre-slaughter handling, stress and pain associated with restraint, whether the incision is painful or not, and the onset of unconsciousness have been put forward, but no consensus has been achieved. There is a need to strike a balance between halal bleeding in the light of science and animal welfare. There is a paucity of scientific data with respect to animal welfare, particularly the use of restraining devices, animal handling, and efficient halal bleeding. However, this review found that competent handling of animals, proper use of restraining devices, and the efficient bleeding process that follows halal slaughter maintains meat eating quality. In conclusion, halal bleeding, when carried out in accordance with recommended animal welfare procedures, will not only maintain the quality and wholesomeness of meat but could also potentially reduce suffering and pain. Maintained meat quality increases consumer satisfaction and food safety.
\end{abstract}

Keyword: Halal slaughter; Religious slaughter of animals; Animal handling; Animal welfare; Animal transport; Meat quality 